\title{
Interaction between opium replacement therapies and HIV treatment coverage
}

Fardad Doroudi ${ }^{1}$ and Ali-Reza Vassigh ${ }^{2}$

${ }^{1}$ UNAIDS Country Director, Islamic Republic of Iran. ${ }^{2}$ UNAIDS Strategic Information Adviser, Islamic Republic of Iran. (Correspondence to: Fardad Doroudi: DoroudiF@unaids.org).

Citation: Doroudi F; Vassigh A-R. Interaction between opium replacement therapies and HIV treatment coverage. East Mediterr Health J. 2020;26(3):257-259. https://doi.org/10.26719/2020.20.3.257

Received: 08/12/19; accepted: 21/12/19

Copyright (C) World Health Organization (WHO) 2020. Open Access. Some rights reserved. This work is available under the CC BY-NC-SA 3.0 IGO license (https://creativecommons.org/licenses/by-nc-sa/3.o/igo).

People who use and inject drugs are among the groups at highest risk of exposure to HIV but remain marginalized and out of reach of health and social services. People who inject drugs are around 28 times more likely to be living with HIV than the general population (1). New infections among people who inject drugs rose by $33 \%$ from 2011 to 2015, and nearly one-third of global HIV infections outside sub-Saharan Africa are caused by injecting drug use, and more than 150000 people who inject drugs became newly infected with HIV in 2015 (1).

HIV prevalence among people who inject drugs has remained essentially unchanged since 2008, while seemingly increased in the Middle East and North Africa (MENA) region $(2,3)$. According to the Global Burden of Disease 2013 study, injecting drug use caused $4.0 \%$ of DALYs due to HIV, with injecting drug use-attributable HIV burden highest in low- to-middle-income countries (4). In the MENA region, the burden of HIV disease attributable to injecting drug use increased from a mean 4000 (1000-15 000) DALYs in 1990 to a mean 91000 (45 000-164 000) DALYs in 2013 (4).

Coverage of opioid substitution therapy interventions remains poor at the global level, not to mention in the MENA region, and is insufficient to prevent, halt, or reverse HIV and HCV epidemics among people who inject drugs (5). However, in contexts where opioid substitution therapy and adherence to antiretroviral therapy support programs are widely accessible, comparable levels of survival are observed among HIV-positive people who inject drugs and people living with HIV (PLHIV) who do not inject drugs (6).

Any single intervention, even with high coverage, is likely to have a minor effect on HIV transmission unless implemented concurrently with other strategies. The benefit and cost-effectiveness of combined approaches to HIV prevention have been repeatedly shown through empirical evidence and model-based projection studies. Many novel interventions, such as mobile needle and syringe programmes and pre-exposure prophylaxis (PrEP), especially as part of a comprehensive package (7), and peer-run supervised injection facilities also have promise for HIV prevention, as have modifications to existing strategies, such as facilitating assisted injection (8-11). The cost-effectiveness ratios for people who inject drugs regardless of HIV status are highly favourable for all regions, with costs per HIV infection averted ranging from US\$ 100 to $\$ 1000$ (11).

Opioid substitution therapy, needle-syringe programmes, and antiretroviral therapy together have established effectiveness in reducing drug dependency, reduced needle-sharing, improve quality of life and averting HIV infections (11). The effects are more than additive since opioid agonist therapy itself positively reduces HIV transmission (12) and is associated with antiretroviral therapy initiation, coverage, adherence, retention and viral load suppression among HIV-positive people who inject drugs $(12-15)$. Scaling up opioid agonist therapy duration and coverage, including in prisons, would decrease all-cause mortality and avert $25.3-56.2 \%$ of HIV-related deaths over 20 years, although the lowest risk of death is seen when opioid substitution therapy and antiretroviral therapy are used jointly (16-18). Among prisoners and detainees, combining opioid agonist therapy with post-release antiretroviral therapy retention would achieve a further reduction in HIV incidence, ranging from $0.3 \%$ to $4.2 \%$ depending on HIV prevalence and programme coverage (19).

In one of the first prospective, longitudinal studies on the cascade of HIV care among key populations in lowand middle-income countries, Januraga et al. reported strikingly poor rates of retention in treatment and viral suppression, and note that attrition at each step of the care cascade needs to be well defined and understood, so that future interventions can be suitably tailored and targeted to meet the needs of the most affected key populations in each country (20).

In conclusion, countries where injecting drug use remains an important driver of the HIV epidemic need to begin and maintain large-scale comprehensive harm reduction programmes (9), in an effort to reach the most underserved populations, be they incarcerated or in the community, and to react rapidly to potential threats (21). 
However, the re-emergence of epidemics among people who inject drugs underlines how vulnerable this population is to changes in the economic, social, and drugmarket scene and how fragile the success of interventions can be in preventing HIV outbreaks (21). The Johns Hopkins-Lancet Commission on Drug Policy and Health not only makes a clear recommendation to invest in treatment for HIV, HCV infection, tuberculosis, and drug dependence, it also emphasizes the need to make harm reduction measures a central pillar of health systems and drug policy, to formulate policies that do not harm women, and to include health, human rights, and development in metrics to judge success of drug policy (22).

Prevention of HIV infection needs high coverage and combined approaches. Governments, policy-makers, and public-health officials must be engaged and convinced of the importance of scaling up. We know enough about what can be effective in prevention of HIV infection. The challenge is to deliver these programmes well, and to scale (10). This comprehensive, sustained approach offers the most effective path to improve treatment coverage, achieve the 90-90-90 goals (23) and end AIDS among people who inject drugs, by 2030.

\section{References}

1. UNAIDS. Harm reduction saves lives. Geneva: UNAIDS; 2017.

2. Degenhardt L, Peacock A, Colledge S, Leung J, Grebely J, Vickerman P, et al. Global prevalence of injecting drug use and sociodemographic characteristics and prevalence of HIV, HBV, and HCV in people who inject drugs: a multistage systematic review. The Lancet Global Health. 2017;5(12):e1192-e207. doi: 10.1016/S2214-109X(17)30375-3.

3. Mathers BM, Degenhardt L, Phillips B, National Drug and Alcohol Research Centre UoNSW, Sydney, Australia, Wiessing L, Crime and Markets Unit EMCfDaDA, Lisbon, Portugal, et al. Global epidemiology of injecting drug use and HIV among people who inject drugs: a systematic review. The Lancet. 2008;372(9651):1733-45. doi: 10.1016/So140-6736(08)61311-2. PubMed PMID: 18817968.

4. Degenhardt L, Charlson F, Stanaway J, Larney S, Alexander LT, Hickman M, et al. Estimating the burden of disease attributable to injecting drug use as a risk factor for HIV, hepatitis C, and hepatitis B: findings from the Global Burden of Disease Study 2013. The Lancet Infectious Diseases. 2016;16(12):1385-98. doi: 10.1016/S1473-3099(16)30325-5.

5. Larney S, Peacock A, Leung J, Colledge S, Hickman M, Vickerman P, et al. Global, regional, and country-level coverage of interventions to prevent and manage HIV and hepatitis $C$ among people who inject drugs: a systematic review. Lancet Glob Health. 2017;5(12):e1208-e20. Epub 2017/10/28. doi: 10.1016/s2214-109x(17)30373-x. PubMed PMID: 29074410; PubMed Central PMCID: PMCPMC5683737.

6. Parashar S, Collins AB, Montaner JS, Hogg RS, Milloy MJ. Reducing rates of preventable HIV/AIDS-associated mortality among people living with HIV who inject drugs. Curr Opin HIV AIDS. 2016;11(5):507-13. Epub 2016/06/03. doi: 10.1097/ coh.0000000000000297. PubMed PMID: 27254749; PubMed Central PMCID: PMCPMC5055433.

7. Marshall BD, Milloy MJ. Improving the effectiveness and delivery of pre-exposure prophylaxis (PrEP) to people who inject drugs. Addiction. 2017;112(4):580-2. Epub 2016/10/13. doi: 10.1111/add.13597. PubMed PMID: 27730702; PubMed Central PMCID: PMCPMC6659115.

8. Reddon H, Marshall BDL, Milloy MJ. Elimination of HIV transmission through novel and established prevention strategies among people who inject drugs. Lancet HIV. 2019;6(2):e128-e36. Epub 2018/12/19. doi: 10.1016/s2352-3018(18)30292-3. PubMed PMID: 30558843; PubMed Central PMCID: PMCPMC6599632.

9. UNODC I, UNAIDS, UNDP, UNFPA, WHO, USAID, PEPFAR. Implementing comprehensive HIV and HCV programmes with people who inject drugs. WHO. 2017. doi: /entity/hiv/pub/idu/hiv-hcv-idu/en/index.html.

10. Degenhardt L, Mathers B, Vickerman P, Rhodes T, Latkin C, Hickman M. Prevention of HIV infection for people who inject drugs: why individual, structural, and combination approaches are needed. Lancet. 2010;376(9737):285-301. Epub 2010/07/24. doi: 10.1016/s0140-6736(10)60742-8. PubMed PMID: 20650522.

11. Wilson DP, Donald B, Shattock AJ, Wilson D, Fraser-Hurt N. The cost-effectiveness of harm reduction. Int J Drug Policy. 2015;26 Suppl 1:S5-11. Epub 2015/03/03. doi: 10.1016/j.drugpo.2014.11.007. PubMed PMID: 25727260.

12. Miller WC, Hoffman IF, Hanscom BS, Ha TV, Dumchev K, Djoerban Z, et al. A scalable, integrated intervention to engage people who inject drugs in HIV care and medication-assisted treatment (HPTN 074): a randomised, controlled phase 3 feasibility and efficacy study. The Lancet. 2018;392(10149):747-59. doi: 10.1016/So140-6736(18)31487-9.

13. Mlunde LB, Sunguya BF, Mbwambo JK, Ubuguyu OS, Yasuoka J, Jimba M. Association of opioid agonist therapy with the initiation of antiretroviral therapy - a systematic review. Int J Infect Dis. 2016;46:27-33. Epub 2016/04/06. doi: 10.1016/j.ijid.2016.03.022. PubMed PMID: 27044520.

14. Low AJ, Mburu G, Welton NJ, May MT, Davies CF, French C, et al. Impact of Opioid Substitution Therapy on Antiretroviral Therapy Outcomes: A Systematic Review and Meta-Analysis. Clin Infect Dis. 2016;63(8):1094-104. Epub 2016/06/28. doi: 10.1093/ cid/ciw416. PubMed PMID: 27343545; PubMed Central PMCID: PMCPMC5036913.

15. Mazhnaya A, Marcus R, Bojko MJ, Zelenev A, Makarenko I, Pykalo I, et al. Opioid Agonist Treatment and Improved Outcomes at Each Stage of the HIV Treatment Cascade in People Who Inject Drugs in Ukraine. J Acquir Immune Defic Syndr. 2018;79(3):288- 
95. Epub 2018/10/13. doi: 10.1097/qai.0000000000001827. PubMed PMID: 30312275.

16. Kamarulzaman A, Altice FL. Challenges in managing HIV in people who use drugs. Curr Opin Infect Dis. 2015;28(1):10-6. Epub 2014/12/10. doi: 10.1097/qco.0000000000000125. PubMed PMID: 25490106; PubMed Central PMCID: PMCPMC4409950.

17. DeBeck K, Cheng T, Montaner JS, Beyrer C, Elliott R, Sherman S, et al. HIV and the criminalisation of drug use among people who inject drugs: a systematic review. The Lancet HIV. 2017;4(8):e357-e74. doi: 10.1016/S2352-3018(17)30073-5.

18. Stone J, Fraser H, Lim AG, Walker JG, Ward Z, MacGregor L, et al. Incarceration history and risk of HIV and hepatitis C virus acquisition among people who inject drugs: a systematic review and meta-analysis. The Lancet Infectious Diseases. 2018;18(12):1397-409. doi: 10.1016/S1473-3099(18)30469-9.

19. Dolan K, Wirtz AL, Moazen B, Ndeffo-mbah M, Galvani A, Kinner SA, et al. Global burden of HIV, viral hepatitis, and tuberculosis in prisoners and detainees. The Lancet. 2016;388(10049):1089-102. doi: 10.1016/So140-6736(16)30466-4.

20. Januraga PP, Reekie J, Mulyani T, Lestari BW, Iskandar S, Wisaksana R, et al. The cascade of HIV care among key populations in Indonesia: a prospective cohort study. The Lancet HIV. 2018;5(10):e560-e8. doi: 10.1016/S2352-3018(18)30148-6.

21. Sypsa V. Why do HIV outbreaks re-emerge among people who inject drugs? The Lancet HIV. 2019;6(5):e274-e5. doi: 10.1016/ S2352-3018(19)30079-7.

22. Csete J, Kamarulzaman A, Kazatchkine M, Altice F, Balicki M, Buxton J, et al. Public health and international drug policy. Lancet. 2016;387(10026):1427-80. Epub 2016/03/30. doi: 10.1016/s0140-6736(16)00619-x. PubMed PMID: 27021149; PubMed Central PMCID: PMCPMC5042332.

23. UNAIDS. 90-90-90: Treatment for all. Geneva: UNAIDS; 2014 (https://www.unaids.org/sites/default/files/media_asset/90-90-90_ en.pdf) 